\title{
The use of NIRS for prediction of intake, digestibility and diet composition in sheep fed mixed grain:roughage diets*
}

\author{
O.L. Valiente ${ }^{1}$, D. Andueza ${ }^{2,4}$ A. de Vega ${ }^{1,3}$, G. Olmos ${ }^{1}$ and F. Muñoz ${ }^{2}$ \\ ${ }^{1}$ Departamento de Producción Animal y Ciencia de los Alimentos, Universidad de Zaragoza \\ Miguel Servet 177, 50013 Zaragoza, Spain \\ ${ }^{2}$ Centro de Investigación y Tecnología Agroalimentaria, Diputación General de Aragón \\ Avenida de Montañana, 930, 50059 Zaragoza, Spain
}

\begin{abstract}
Sixteen adult sheep fed on different proportions of barley grain and straw $(60: 40,45: 55,30$ : 70 and 15:85) were used to obtain regression equations for prediction of dry matter (DMI) and digestible organic matter (DOMI) intake, dry matter (DMD), organic matter (OMD), crude protein (CPD) and neutral detergent fibre (NDFD) digestibility, and proportion of straw consumed (\% straw) from the NIRS analysis of the faeces. All equations had coefficients of determination in calibration higher than 0.65 , except that for the prediction of NDFD $\left(\mathrm{R}^{2}=0.11\right)$. The coefficients of determination in cross-validation were much lower, with only DMD, OMD and \% straw predictions showing values higher than 0.70 .
\end{abstract}

KEY WORDS: sheep, barley, intake, digestibility, diet composition, NIRS

\section{INTRODUCTION}

Mixed barley grain:straw diets are very common in many areas of the world, either indoors or using the standing whole plant as pasture in summer. Faecal nalkane concentrations in sheep fed these diets are quite low and variable (Valiente et al., 2003), this fact largely affecting their recovery (Brosh et al., 2003) and hence the estimation of intake, digestibility and diet composition. The exploration of new techniques for this purposes, especially in grazing conditions, appears then worthwhile.

\footnotetext{
* Supported by the Spanish Ministry for Science and Technology, Research Project AGL2001-2771

${ }^{3}$ Corresponding author: e-mail: avega@posta.unizar.es

${ }^{4}$ Present address: INRA-Theix URH-DVA 63122 Saint Genès Champanelle, France
} 
Near infrared reflectance spectroscopy (NIRS) of faecal spectra may be a feasible tool for the assessment of the quality of animal diets (Givens and Deaville, 1999), but to the authors' knowledge all the studies have been carried out separately with forages or concentrates, and no data appear to be available from mixed diets.

The aim of the present work was then to check the possibility of predicting DMI, DOMI, DMD, OMD, CPD, NDFD and \% straw consumed through the NIRS analysis of faeces from sheep fed different combinations of barley grain and straw.

\section{MATERIAL AND METHODS}

\section{Animals and diets}

Sixteen adult Rasa Aragonesa ewes were allocated to 4 treatments consisting of different proportions of whole barley grain and straw chopped to $5 \mathrm{~cm}(60: 40,45$ : $55,30: 70$ and 15:85).

\section{Experimental management}

The experimental diets were offered once daily (at $09.00 \mathrm{~h}$ ) at a restricted level which was set for each animal during the preliminary period, in order to minimize refusals. Grain was offered in the first instance followed by the straw.

The experiment's first 18 days were for adaptation to the diets. Animals were then placed in metabolism crates and a 7-day digestibility trial was performed after a 5-day adaptation period. During the balance period, daily samples of grain and straw (and refusals when they occurred) were taken and pooled for the whole period. Half the sample was dried at $60^{\circ} \mathrm{C}$ for $48 \mathrm{~h}$ and used to determine chemical composition. Faeces were collected daily and oven dried at $60^{\circ} \mathrm{C}$ to estimate DM content, after taking a subsample (5\% on weight basis) which was kept frozen until the end of the collection period, pooled on an individual animal basis and freeze-dried for chemical composition and analysis of NIRS spectra.

\section{Analytical procedures}

Dry matter (DM) in feeds was determined by drying at $100{ }^{\circ} \mathrm{C}$ for $24 \mathrm{~h}$, and organic matter $(\mathrm{OM})$ by ashing at $550^{\circ} \mathrm{C}$ for $8 \mathrm{~h}$. Total nitrogen $(\mathrm{N})$ was determined following the Kjeldahl method using Se as catalyst and a Kjeltec Auto 1030 Analyser. Neutral detergent fibre (NDF) was measured with a Fibertec 1020 Hot Extractor Analyser, on dried samples $\left(60^{\circ} \mathrm{C}\right.$ for $\left.48 \mathrm{~h}\right)$, as described by Van Soest et al. (1991), and expressed as ash-free residues. Faecal samples were also analysed for DM, OM, N and NDF.

\section{NIR analysis and development of calibrations}

Ground faecal samples were used to obtain calibration equations for DMD, OMD, CPD, NDFD, DMI, DOMI and the proportion of straw consumed. 
NIR data from 700 to $2500 \mathrm{~nm}$ were collected using a Foss NIRSystems 6500 monochromator equipped with a sample transport module. Spectra and reference data were recorded with the Infrasoft International (ISI) software NIRS2 ver. 2.4 (NIRSystems Inc., Silver Spring, MD, USA). Modified partial squares regression methods (MPLS) were used for equations' development after a first derivative transformation of the spectral data and a scatter correction treatment (standard normal variate and detrend (SNVD)) (Barnes et al., 1989). To assess the prediction performance of NIR equations, the main statistics used were the standard error of calibration (SEC), the standard error of crossvalidation (SECV), the standard error of the reference method (SEL), the determination coefficient in calibration $\left(\mathrm{R}^{2} \mathrm{c}\right)$ and the determination coefficient in cross-validation $\left(\mathrm{R}^{2} \mathrm{cv}\right)$.

\section{RESULTS}

Table 1 shows the performances of the different calibrations obtained. Strong correlations were found for DMI, DMD, OMD and percentage of straw consumed, whereas predictions of DOMI and CPD were less precise and NIRS estimation of NDFD was not possible in the present conditions. Although the $\mathrm{R}^{2} \mathrm{cV}$ were consistently lower than $\mathrm{R}^{2} \mathrm{c}$, except for \% of straw consumed, SECV values were less than $20 \%$ higher than SEL for DMI, DMD and OMD.

Table 1. Performances of NIR predictions of dry matter (DMI) and digestible organic matter (DOMI) intake $\left(\mathrm{g} / \mathrm{W}^{0.75}\right)$, dry matter (DMD), organic matter (OMD), crude protein (CPD) and neutral detergent fibre (NDFD) digestibility, and \% straw actually consumed ( $\%$ straw) by sheep fed different proportions of barley grain and straw (60:40, 45:55, 30:70 and 15:85)

\begin{tabular}{lllllccc}
\hline \multirow{2}{*}{ Item } & & \multicolumn{2}{c}{ Calibration } & & \multicolumn{2}{c}{ Cross-validation } & \\
\cline { 3 - 4 } & $\mathrm{N}$ & $\mathrm{R}^{2} \mathrm{c}$ & $\mathrm{SEC}$ & & $\mathrm{R}^{2} \mathrm{cV}$ & $\mathrm{SECV}$ & SEL \\
\hline DMI & 15 & 0.83 & 1.96 & & 0.45 & 3.58 & 3.39 \\
DOMI & 15 & 0.75 & 1.72 & & 0.40 & 2.73 & 2.08 \\
DMD & 15 & 0.85 & 1.91 & & 0.74 & 2.68 & 2.24 \\
OMD & 15 & 0.85 & 1.91 & & 0.75 & 2.66 & 2.36 \\
CPD & 15 & 0.65 & 6.36 & & 0.55 & 7.72 & 4.40 \\
NDFD & 16 & 0.11 & 2.93 & & 0.00 & 3.32 & 2.55 \\
\% straw & 16 & 0.84 & 6.50 & & 0.81 & 7.71 & 1.93 \\
\hline
\end{tabular}

$\mathrm{N}$ - number of samples; $\mathrm{R}^{2} \mathrm{c}$-coefficient of determination in calibration; SEC - standard error of calibration; $\mathrm{R}^{2} \mathrm{cv}$ - coefficient of determination in cross-validation; SECV - standard error of crossvalidation; SEL - standard error of reference method

\section{DISCUSSION}

Although strong relationships between NIR calibration and most of the intake and digestibility parameters have been found, differences between $\mathrm{R}^{2} \mathrm{c}$ and $\mathrm{R}^{2} \mathrm{cv}$ 
values (mainly for DMI and DOMI) indicate that the robustness of the model can be improved. The low number of samples may not be enough to obtain robust equations, especially when most of the data from one animal had to be withdrawn because they were statistically out of range (Table 1). On the other hand, the close values of SECV and SEL indicate the low error of NIRS measurements for DMI, DMD and OMD. The worse estimations of CPD may be explained, at least in part, by the variation introduced by the low crude protein contents of the diets and the consequent increased importance of the endogenous secretions. Concerning the NDFD, NIRS models usually do not perform well (Jung and Lamb, 2003) as NDF cannot be considered a specific biochemical component of feeds, and NDFD is strongly dependent on the presence of others structures.

\section{CONCLUSIONS}

Intake, \% straw consumed and DMD and OMD, may be successfully predicted in sheep fed mixed barley grain:straw diets by NIRS. Hence there is a possibility for the technique to be used, alone or in combination with other methods, in grazing conditions where complex mixtures are in offer for the estimation of intake, digestibility and diet selection. Larger number of samples, however, are needed in order to improve the prediction performances of NIRS models.

\section{REFERENCES}

Barnes R.J., Dhanoa M.S., Lister S.J., 1989. Standard normal variate transformation and detrending of near infrared diffuse reflectance spectra. Appl. Spectrosc. 43, 772-777

Brosh A., Henkin Z., Rothman S.J., Aharoni Y., Orlov A., Arieli A., 2003. Effects of faecal n-alkane recovery in estimates of diet composition. J. Agr. Sci. 140, 93-100

Givens D.I., Deaville E.R., 1999. The current and future role of near infrared reflectance spectroscopy in animal nutrition: a review. Aust. J. Agr. Res. 50, 1131-1145

Jung H.G., Lamb J.F.S., 2003. Identification of lucerne stem cell wall traits related to in vitro neutral detergent fibre digestibility. Anim. Feed Sci. Tech. 110, 17-29

Valiente O.L., Delgado P., de Vega A., Guada J.A., 2003. Validation of the n-alkane technique to estimate intake, digestibility, and diet composition in sheep consuming mixed grain:roughage diets. Aust. J. Agr. Res. 54, 693-702

Van Soest P.J., Robertson J.B., Lewis B.A., 1991. Methods for dietary fiber, neutral detergent fiber, and nonstarch polysaccharides in relation to animal nutrition. J. Dairy Sci. 74, 3583-3597 